\title{
Adaptação transcultural da Sport Character Scale no Brasil
}

\author{
Cross-Cultural adaptation of Sport Character Scale in Brazil
}

Adaptación transcultural de la Sport Character Scale en Brasil

\author{
JONAS YUITI OGAWA ${ }^{1}$; ANGEla NOGUEIRA NEVES ${ }^{2}$ \\ Escola de EduCaÇão Física do ExérCito, ESEFEX, Rio de JaNEIro-RJ, BRASIL
}

\begin{abstract}
RESUMO
Objetivo: adaptar culturalmente a Sport Character Scale para a língua portuguesa no Brasil. Metodologia: adotou-se guia que prevê a execução de cinco passos: tradução, síntese, retrotradução, comitê de peritos e préteste. Doze voluntários, todos homens e atletas participaram dos pré-testes. Resultados: duas traduções foram realizadas e uma versão de síntese foi enviada para duas retrotraduções. As versões original, traduzida e retrotraduzida foram avaliadas quanto às equivalências cultural, idiomática, semântica e de conteúdo por um comitê de juízes especialistas, gerando em uma versão preliminar da escala. No primeiro pré-teste da versão aprovada pelos peritos surgiram dúvidas em sete itens, que após consulta ao autor original do instrumento foram modificados e levados a um segundo pré-teste, no qual a escala foi aprovada em termos de clareza, pertinência dos itens, layout e consistência de repostas. Conclusão: a escala foi adaptada culturalmente e está pronta para ser levada a um estudo psicométrico.
\end{abstract}

Palavras-chave: Adaptação Transcultural. Avaliação. Caráter. Esporte.

\begin{abstract}
Objective: to cross-culturally adapt the Sport Character Scale into the Portuguese language in Brazil. Methodology: we adopted a guideline, which determines five steps: translation, synthesis, back-translation, experts' committee, and pretest. Twelve volunteers, all men and athletes were recruited for pretests. Results: two translations were made, and the synthesis was sent to two back translations. The original, translated and backtranslated versions were evaluated by a experts' committee who analyzed semantic, idiomatic, conceptual, and cultural equivalences of each item, building a preliminary version. In the first pretest of the version approved by the experts, doubts emerge in seven items, which after consultation with the original author of the instrument were modified and led to a second pretest, in which the scale was approved in terms of clarity, the relevance of items, layout, and consistency of responses. Conclusion: the scale was cross-culturally adapted and is ready to be submitted to a psychometric study.
\end{abstract}

Keywords: Cross-Cultural Adaptation. Evaluation. Character. Sport.

\section{RESUMEN}

Objetivo: adaptar transculturalmente la Escala de carácter deportivo al idioma portugués en Brasil. Metodología: adoptamos una guía, que determina cinco pasos: traducción, síntesis, retrotraducción, comité de expertos y prueba preliminar. Se reclutó a doce voluntarios, todos hombres y atletas, para las pruebas preliminares. Resultados: se realizaron dos traducciones y la síntesis se envió a dos traducciones posteriores. Las versiones original, traducida y retro-traducida fueron evaluadas por un comité de expertos que analizó las equivalencias semánticas, idiomáticas, conceptuales y culturales de cada ítem, construyendo una versión preliminar. En el primer pretest de la versión aprobada por los expertos surgen dudas en siete ítems, que tras consulta con el autor original del instrumento fueron modificados y derivaron en un segundo pretest, en el que se aprobó la escala en cuanto a claridad, relevancia de elementos, diseño y coherencia de las respuestas. Conclusión: la escala fue adaptada transculturalmente y está lista para ser sometida a un estudio psicométrico.

Palabras clave: Adaptación Transcultural. Evaluación. Carácter. Deporte.

\footnotetext{
1 Graduado em Educação Física pela ESEFEX. E-mail: jonasogawa25@gmail.com. ORCID: http://orcid.org/0000-0003-3679-6007.

2 Professora do Magistério Superior da ESEFEX. E-mail: angelanneves@yahoo.com.br. ORCID: http://orcid.org/0000-0001-8304-1040.
} 


\section{INTRODUÇÃO}

Caráter e personalidade são palavras frequentemente empregadas como sinônimas. De acordo com o dicionário de psicologia da American Psychological Association (APA) (VANDENBOS, 2010) caráter é o conjunto de atributos de um indivíduo somado com seus traços de personalidade, tais como suas crenças religiosas, seus valores sociais e suas atitudes morais. O somatório destes atributos define os traços de caráter, formados a partir de padrões morais e éticos definidos pela sociedade, regulando a forma com que os indivíduos irão agir e se expressar, fundamentados em seus valores (VANDENBOS, 2010).

O conceito de personalidade está relacionado com os ajustes e adaptações de um indivíduo à vida. A APA (VANDENBOS, 2010) define como personalidade a integração de comportamentos (interesses, impulsos, valores, padrões emocionais) e características (hereditariedade, experiências, relacionamentos críticos), que ajudam a determinar a reação das pessoas diante de situações específicas. Tal integração define os traços de personalidade, que pode ser útil para explicar e prever a reação dos indivíduos, visto que possibilita a dedução de um padrão de comportamentos, sentimentos, hábitos e atitudes (VANDENBOS, 2010). Uma forma eficaz de abordagem do caráter é como uma virtude ou característica pessoal. As pessoas que possuem uma ampla gama de virtudes positivas possuem um bom caráter moral (SHIELDS; BREDEMEIER, 1995).

A ideia de que o esporte e a atividade física ajudam a construir o caráter é, na verdade, uma concepção antiga. Ao escrever sua obra República, Platão (2017) afirmou que a educação exclusivamente acadêmica é condenada. Para o autor, a formação sem atividade física produz pessoas suaves e supersensíveis e então, seria necessária uma combinação entre os conhecimentos acadêmicos e as práticas físicas, para a produção de mentes corajosas e civilizadas (PLATÃO, 2017). A permanência dessa perspectiva no tempo pode ser vista em outra obra icônica, como Emílio, de Rousseau (2017), publicada originalmente em 1792. Rousseau afirma que tornar o corpo forte e saudável é de suma importância para que ele seja bom e sábio. Para ele, um corpo fraco faz uma mente fraca (ROUSSEAU, 2017). É sob essa proposição de que o esporte educa socialmente o homem, que o Barão de Coubertin, em um discurso em 1929, caracterizou o técnico de rugby Thomas Arnold como o maior educador da era moderna, tendo ele mesmo feito seus músculos servos de seu caráter (POLLEY, 2012).

O esporte é concebido, sob estes pontos de vista, como um veículo para sedimentação das características positivas do caráter: senso de justiça, igualdade, integridade, honestidade, entre outras. As pessoas que possuem tais traços tendem a demonstrar ação moral no esporte, tendo em vista que suas ações serão pautadas em seus princípios éticos e morais (PARK, 2007). Todavia, uma questão que não pode ser ignorada, em todos os níveis competitivos, é a prevalência de comportamentos amorais e da existência de atletas que apresentam "mau caráter" (SHIELDS; BREDEMEIER, 1995). Escândalos como a utilização de drogas, o desrespeito das regras para gerar benefícios e a existência de fraudes são também parte do fenômeno esportivo, em oposição às virtudes morais que o mesmo pode desenvolver no atleta. A maneira com que os atletas se comportam no esporte é diferente da "vida real": a competitividade e o desejo de vencer coíbem a ação moral em campo. Isso ocorre na crença de que dentro de um contexto esportivo vale tudo, e, diante da crença de que o esporte vai além da vida real, os atletas são encorajados (internamente encorajados por seu desejo, ou externamente, pelas regras da equipe, pela postura do técnico e companheiros) a ter comportamentos repugnantes ou inadequados (SHIELDS; BREDEMEIER, 1995). Assim, a necessidade de avaliar e verificar quais características (a)morais estavam presentes entre os atletas se faz relevante (KAVUSSANU; BORADLEY, 2009).

Já existem medidas sistematizadas na literatura para avaliar o caráter e a personalidade no esporte. Um exemplo é a Multidimensional Sports Personship Orientation Scale (MSOS), 
que foi desenvolvida a partir das experiências vividas pelos próprios atletas (VALLERAND et al., 1997). Consta de cinco itens, os quais abordam o compromisso com a participação, o respeito pelas convenções sociais, às regras e funcionários, o respeito pelos oponentes e uma abordagem negativa da participação de atletas. A principal limitação da MSOS é não possuir uma variabilidade de itens grande o bastante para ser utilizada em outras modalidades, que não as coletivas. Os próprios autores, após sua confecção, alegaram ainda haver espaço para a criação e elaboração de uma escala com maior variedade de itens, visando alcançar uma maior abrangência de situações esportivas (VALLERAND et al., 1997)

Outra medida existente é a Attitudes to Moral Decision-making in Youth Sport Questionnaire (AMDYSQ), composta de 15 itens distribuídos em três fatores, sendo eles o antidesportivismo, a trapaça e a vitória justa. Foi especialmente direcionada a um grupo com etário muito jovem e em maturação, sujeito a mudanças comportamentais e de pensamentos constantes, sendo para eles sua principal indicação de uso (LEE; WHITEHEAD; NTOUMANIS, 2007).

Mais recentemente, em 2013, considerando os passos já trilhados pelas medidas anteriormente citadas e avançando na teoria de medidas, é criada a Sport Character Scale (SCS) (JANG, 2013) para avaliar a contribuição do esporte na formação, desenvolvimento e na determinação de características do caráter do atleta. A SCS tem 27 itens, ordenados em cinco fatores que agrupam as características: compaixão (itens 16 a 21), espírito esportivo (itens 22 a 24), atitude antissocial (itens 11 a 15), integridade (itens 1 a 10) e justiça (itens de 25 a 27). As respostas são dispostas em uma escala Likert, não forçada, de 6 pontos (1= discordo totalmente, $6=$ concordo totalmente). Maiores escores obtidos após o preenchimento indicam maior aderência àquela qualidade de caráter representada pelo fator.

Com base na literatura e teorias de caráter esportivo, a nova medida de caráter buscou se basear no modelo de ação moral e seu autor procurou a validação da medida através do exame das relações entre o caráter no esporte e outras variáveis psicológicas (JANG, 2013). Com a criação da SCS, passou a existir uma medida de uso amplo e consistente que possibilita o fornecimento de uma imagem mais completa do caráter do atleta para pesquisadores e profissionais e, ao mesmo tempo, examina as relações entre respostas motivacionais e sua contribuição na formação do caráter (JANG, 2013).

No Brasil, a SCS ainda não está disponível para uso, conforme identificado em nosso levantamento bibliográfico em bases de dados, justificando a importância deste trabalho científico no que tange a sua adaptação cultural para nosso idioma.

Quando se pretende utilizar um instrumento de outra língua ou outra cultura, é preciso, primeiramente, adaptar transculturalmente o mesmo, para em seguida, proceder com a validação psicométrica em uma amostra de referência no país alvo (BEATON et al., 2007). Adaptar culturalmente um instrumento existente em outra língua se justifica porque é o caminho mais econômico para o pesquisador, além de favorecer diálogo com outros estudos que usaram os mesmos instrumentos em outros países (BEATON et al., 2007).

Face ao exposto, o objetivo do estudo foi adaptar culturalmente para a Língua Portuguesa no Brasil e gerar evidências de validade de conteúdo da SCS.

\section{Metodologia}

Foi feito o contato, inicialmente, com o autor da SCS para que fosse realizada a adaptação cultural do instrumento desenvolvido por ele para a língua portuguesa. $\mathrm{O}$ autor, inclusive, se ofereceu para eventuais retiradas de dúvidas, permitindo a realização do estudo. Para a adaptação cultural, foram seguidos cinco passos, como preconizados por Beaton et al. 
(2007), incluindo as sugestões de Ferreira et al. (2014) em relação ao tamanho amostral para pré-teste e a configuração da reunião de peritos (figura 1).

Figura 1: Procedimentos metodológicos.

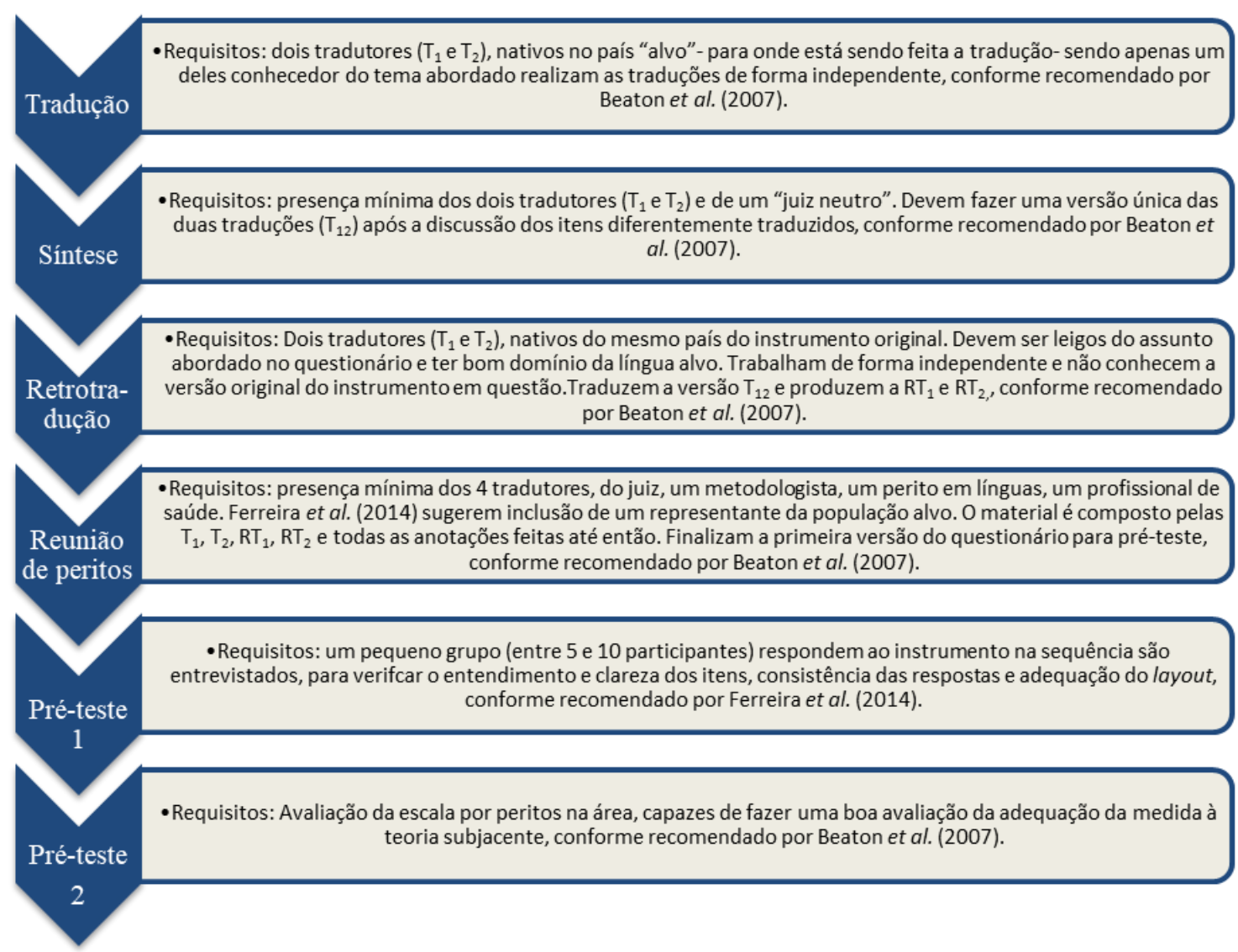

Fonte: Adaptada de Beaton et al. (2007) e Ferreira et al. (2014).

A seleção amostral foi do tipo não-probabilística, por julgamento, recrutada para a realização da etapa de pré-teste da escala. A população de interesse foram atletas de modalidades coletivas.

Para a primeira fase do pré-teste foram recrutados dois grupos de 6 participantes, seguindo as recomendações de Ferreira et al. (2014) que versam sobre uma adaptação nessa fase específica do guia de Beaton et al. (2002). No grupo 1, todos os indivíduos eram atletas do sexo masculino e a idade média foi de $26,17 \pm 2,14$ anos. No grupo 2 , igualmente, todos os indivíduos eram atletas do sexo masculino e a idade média foi de 25,67 \pm 1,97anos.

$\mathrm{Na}$ segunda fase do pré-teste, seguindo estritamente Beaton et al. (2007) foram recrutados peritos para a avaliação do instrumento. Foram 4 os juízes que julgaram a clareza e pertinência teórica dos itens aos constructos avaliados (caráter no esporte). Foram 2 profissionais do sexo masculino e 2 do sexo feminino, sendo um psicólogo esportivo, dois professores de educação física pesquisadores na área de psicologia do esporte e um psicometrista, com idades variando entre 30 e 43 anos, com experiência profissional superior a 10 anos.

O processo de adaptação cultural foi analisado de forma descritiva e analítica, seguindo padrões de estudos do tipo metodológico. Em relação à validade de conteúdo, as notas dos juízes foram computadas e foi calculado o índice de validação de conteúdo para cada item (em relação ao julgamento da clareza e pertinência dos itens), segundo a fórmula: $\mathrm{I}-\mathrm{CVI}=\mathrm{n}^{\mathrm{o}}$ juízes que atribuíram nota máxima / $\mathrm{n}^{\circ}$ total de juízes. Valores iguais ou maiores que 0,80 
indicam itens adequados, entre 0,70 e 0,79 itens que podem ter problemas e deve ser avaliada a possibilidade de revisão e abaixo de 0,70 itens que deveriam ser eliminados (ZAMANZADEH et al., 2015).

\section{RESULTADOS}

\section{TRADUÇÃO, SÍNTESE E RETROTRADUÇÃO}

O primeiro passo foi a tradução propriamente dita, em que dois tradutores $\left(T_{1}\right.$ e $\left.T_{2}\right)$, uma comunicadora social e uma professora do magistério federal, eram nativos em língua portuguesa com domínio da língua inglesa. As duas tradutoras realizaram a tradução da escala, de forma independente, sendo apenas uma das tradutoras conhecedora do tema abordado. Observou-se que apenas os itens 6 e 9 foram traduzidos de forma exatamente igual. Os itens $1,4,5,7,8,10,11,12,13,15,16,18,19,20,21,22,23,25,26$ e 27 foram traduzidos de forma semelhante entre si. Já os itens 2, 3, 14 e 24 foram traduzidos de forma um pouco diferente entre si, mas sem grandes discrepâncias.

O segundo passo foi a reunião de síntese, em que os resultados e traduções das duas tradutoras foram submetidos a um "juiz neutro", professora do magistério federal, brasileira, com domínio da língua inglesa, momento no qual foi feita uma versão única, que refletia o consenso das duas traduções $\left(\mathrm{T}_{12}\right)$. Os itens $2,3,14$, e 24 foram redigidos na versão de síntese por uma combinação de $T_{1}$ e $T_{2}$. Os itens 6 e 9, iguais nas duas traduções seguiram para a síntese sem qualquer modificação. Os itens $1,8,12,21,25$ e 26 foram redigidos na versão de síntese conforme proposto na $\mathrm{T}_{1}$, enquanto os itens $4,5,7,10,11,13,15,16,18,19,20,22$, 23 e 27 seguiram para a síntese conforme proposto pela $T_{2}$.

O terceiro passo foi a realização da retrotradução, no qual dois tradutores, falantes nativos de inglês - uma nascida nos Estados Unidos e outro na Jamaica - com domínio da língua portuguesa, leigos no assunto abordado na escala, retrotraduziram a versão $\mathrm{T}_{12}$ para a língua inglesa e produziram a versão $\mathrm{RT}_{1}$ e $\mathrm{RT}_{2}$. Na retrotradução dos itens oriundos da versão síntese, os itens $1,12,13,17,18$ e 19 foram traduzidos para o inglês com o conteúdo igual à versão original da escala. Os itens 2, 22, 23, 24, 25, 26 e 27 obtiveram retrotraduções exatamente iguais entre si, e conteúdo bem semelhante ao da escala original. O item 17 apresentou conteúdo muito próximo ao da escala original. Observando o quadro 1 podemos comparar as versões de tradução e retrotradução, bem como a versão escolhida como síntese para a escala traduzida.

Quadro 1: Resumos da tradução, síntese e retrotradução da SCS.

\begin{tabular}{|c|c|c|c|c|c|c|}
\hline & $\begin{array}{l}\text { Item da versão } \\
\text { original }\end{array}$ & $\begin{array}{l}\text { Versão traduzida } \\
\text { (T1) }\end{array}$ & $\begin{array}{l}\text { Versão traduzida } \\
\text { (T2) }\end{array}$ & $\begin{array}{l}\text { Versão } \\
\text { retrotradução } \\
\text { (RT1) }\end{array}$ & $\begin{array}{l}\text { Versão } \\
\text { retrotradução } \\
(\text { RT2) }\end{array}$ & $\begin{array}{l}\text { Síntese da análise comparativa } \\
\text { da tradução e retrotradução }\end{array}$ \\
\hline 1 & $\begin{array}{l}\text { Even when losing } \\
\text { by a lot of points, I } \\
\text { don't give up. }\end{array}$ & $\begin{array}{l}\text { Mesmo perdendo } \\
\text { por muitos pontos, } \\
\text { eu não desisto. }\end{array}$ & $\begin{array}{l}\text { Mesmo quando eu } \\
\text { estou perdendo por } \\
\text { vários pontos, eu } \\
\text { não desisto. }\end{array}$ & $\begin{array}{l}\text { Even when I'm } \\
\text { losing by several } \\
\text { points, I don't give } \\
\text { up. }\end{array}$ & $\begin{array}{l}\text { Even when I'm } \\
\text { losing by several } \\
\text { points, I don't give } \\
\text { up. }\end{array}$ & $\begin{array}{l}\text { Mesmo quando eu estou } \\
\text { perdendo por vários pontos, eu } \\
\text { não desisto. } \\
\text { Obs.: Optou-se pela ideia de a } \\
\text { diferença de pontos entre as } \\
\text { equipes ser grande. }\end{array}$ \\
\hline 2 & $\begin{array}{l}\text { Whether I win or } \\
\text { lose, I show good } \\
\text { game manners. }\end{array}$ & $\begin{array}{lr}\text { Independentemente } \\
\text { de ganhar ou } \\
\text { perder, eu sempre } \\
\text { demonstro boas } \\
\text { maneiras r no } \\
\text { esporte. }\end{array}$ & $\begin{array}{l}\text { Mesmo que eu } \\
\text { vença ou perca, eu } \\
\text { mostror boas } \\
\text { maneiras no jogo. }\end{array}$ & $\begin{array}{l}\text { Regardless of } \\
\text { winning or losing, } \\
\text { I always play } \\
\text { fairly. }\end{array}$ & $\begin{array}{lr}\text { Regardless } & \text { of } \\
\text { winning or } & \text { losing, } \\
\text { I show good } \\
\text { manners } & \text { of } \\
\text { gameplay. } & \end{array}$ & $\begin{array}{l}\text { Independentemente de ganhar } \\
\text { ou perder, eu demonstro } \\
\text { espírito esportivo. } \\
\text { Obs.: Após a reunião de peritos, a } \\
\text { palavra "boas maneiras" foi } \\
\text { substituída por "espírito } \\
\text { esportivo". }\end{array}$ \\
\hline 3 & $\begin{array}{l}\text { Whether I win or } \\
\text { lose, I am always } \\
\text { courteous. }\end{array}$ & \begin{tabular}{l}
\multicolumn{3}{l}{ Independentemente } \\
de ganhar ou \\
perder, eu sou \\
sempre cortês.
\end{tabular} & $\begin{array}{l}\text { Mesmo que eu } \\
\text { vença ou perca, eu } \\
\text { sempre sou bem- } \\
\text { educado. }\end{array}$ & $\begin{array}{l}\text { Regardless of } \\
\text { winning or losing, } \\
\text { I always } \\
\text { demonstrate "fair } \\
\text { play" and courtesy. }\end{array}$ & $\begin{array}{l}\text { Regardless of } \\
\text { winning or losing, } \\
\text { I'm Always well } \\
\text { educated. }\end{array}$ & $\begin{array}{l}\text { Independentemente de ganhar } \\
\text { ou perder, eu sempre sou } \\
\text { educado. } \\
\text { Obs.: Optou-se pela retirada da } \\
\text { palavra "bem". }\end{array}$ \\
\hline
\end{tabular}


Jonas Yuiti Ogawa; Angela Nogueira Neves

\begin{tabular}{|c|c|c|c|c|c|c|}
\hline & $\begin{array}{l}\text { Item da versão } \\
\text { original }\end{array}$ & $\begin{array}{l}\text { Versão traduzida } \\
\text { (T1) }\end{array}$ & $\begin{array}{l}\text { Versão traduzida } \\
\text { (T2) }\end{array}$ & $\begin{array}{l}\text { Versão } \\
\text { retrotradução } \\
\text { (RT1) }\end{array}$ & $\begin{array}{l}\text { Versão } \\
\text { retrotradução } \\
\text { (RT2) }\end{array}$ & $\begin{array}{l}\text { Síntese da análise comparativa } \\
\text { da tradução e retrotradução }\end{array}$ \\
\hline 4 & $\begin{array}{l}\text { Even if } \begin{array}{r}\text { an } \\
\text { opponent plays }\end{array} \\
\text { unfairly, I always } \\
\text { show good game } \\
\text { manners. }\end{array}$ & $\begin{array}{l}\text { Mesmo que um } \\
\text { adversário jogue de } \\
\text { forma injusta, eu } \\
\text { sempre demonstro } \\
\text { boas maneiras no } \\
\text { esporte. }\end{array}$ & $\begin{array}{l}\text { Mesmo que um } \\
\text { oponente trapaceie, } \\
\text { eu sempre mostro } \\
\text { boas maneiras de } \\
\text { jogo. }\end{array}$ & $\begin{array}{l}\text { Even if an } \\
\text { opponent cheats, I } \\
\text { always show good } \\
\text { manners. }\end{array}$ & $\begin{array}{l}\text { Even if an } \\
\text { opponent cheats, I } \\
\text { always show good } \\
\text { manners. }\end{array}$ & $\begin{array}{l}\text { Mesmo que um adversário } \\
\text { trapaceie, eu sempre mostro } \\
\text { espírito esportivo. } \\
\text { Obs.: A tradução escolhida } \\
\text { manteve a equivalência } \\
\text { semântica, trocando oponente por } \\
\text { adversário. }\end{array}$ \\
\hline 5 & $\begin{array}{l}\text { Regardless of } \\
\text { whether the referee } \\
\text { or coach is } \\
\text { watching, I play } \\
\text { fairly. }\end{array}$ & $\begin{array}{l}\text { Não importa se o } \\
\text { juiz ou o treinador } \\
\text { está olhando, eu } \\
\text { jogo de forma } \\
\text { justa. }\end{array}$ & $\begin{array}{l}\text { Independentemente } \\
\text { do juiz ou técnico } \\
\text { estarem olhando, } \\
\text { eu jogo de forma } \\
\text { justa. }\end{array}$ & $\begin{array}{l}\text { Regardless of } \\
\text { whether the referee } \\
\text { or coach is } \\
\text { looking, I play } \\
\text { fairly. }\end{array}$ & $\begin{array}{l}\text { Even when I get } \\
\text { mad during the } \\
\text { game, I don't try to } \\
\text { upset the opponent. }\end{array}$ & $\begin{array}{l}\text { Independentemente do juiz ou } \\
\text { técnico estarem olhando, eu } \\
\text { jogo de forma justa. } \\
\text { Obs.: A tradução escolhida } \\
\text { manteve a equivalência } \\
\text { semântica. }\end{array}$ \\
\hline 6 & $\begin{array}{l}\text { I always accept the } \\
\text { results of a game. }\end{array}$ & $\begin{array}{l}\text { Eu sempre aceito } \\
\text { os resultados de } \\
\text { um jogo. }\end{array}$ & $\begin{array}{l}\text { Eu sempre aceito } \\
\text { os resultados do } \\
\text { jogo. }\end{array}$ & $\begin{array}{l}\text { I always accept the } \\
\text { results of a game. }\end{array}$ & $\begin{array}{l}\text { I always accept the } \\
\text { result of the game. }\end{array}$ & $\begin{array}{l}\text { Eu sempre aceitos os resultados } \\
\text { de um jogo. } \\
\text { Obs.: a tradução e retrotradução } \\
\text { foram idênticas, mantendo o } \\
\text { sentido literal da frase. }\end{array}$ \\
\hline 7 & $\begin{array}{l}\text { Even if I get mad } \\
\text { during a game, I } \\
\text { don't trash-talk. }\end{array}$ & $\begin{array}{l}\text { Mesmo que eu } \\
\text { fique } \text { zangado } \\
\text { durante o jogo, eu } \\
\text { não insulto. }\end{array}$ & $\begin{array}{l}\text { Mesmo quando eu } \\
\text { fico bravo durante } \\
\text { o jogo, eu não fico } \\
\text { falando bobagem } \\
\text { para atrapalhar. }\end{array}$ & $\begin{array}{l}\text { Even when I get } \\
\text { angry during the } \\
\text { game, I don't use } \\
\text { offensive words to } \\
\text { upset an opponent. }\end{array}$ & $\begin{array}{l}\text { Even when I get } \\
\text { mad during the } \\
\text { game, I don't try to } \\
\text { upset the opponent. }\end{array}$ & $\begin{array}{l}\text { Mesmo quando eu fico bravo } \\
\text { (a) durante o jogo, eu não fico } \\
\text { falando bobagem para } \\
\text { atrapalhar o adversário. } \\
\text { Obs.: Foi feita uma versão síntese } \\
\text { de } T_{1} \text { e } T_{2} \text {, adaptada pela } \mathrm{RT}_{2} \text {, } \\
\text { inserindo a palavra adversário } \\
\text { para melhorar o entendimento da } \\
\text { frase. }\end{array}$ \\
\hline 8 & $\begin{array}{l}\text { Whether I win or } \\
\text { lose, I always do } \\
\text { my best. }\end{array}$ & $\begin{array}{l}\text { Independente de } \\
\text { ganhar ou perder, } \\
\text { eu sempre faço o } \\
\text { meu melhor. }\end{array}$ & $\begin{array}{l}\text { Mesmo que eu } \\
\text { vença ou perca, eu } \\
\text { sempre dou meu } \\
\text { melhor. }\end{array}$ & $\begin{array}{l}\text { Regardless of } \\
\text { winning or losing, } \\
\text { I always do my } \\
\text { best }\end{array}$ & $\begin{array}{l}\text { Regardless of } \\
\text { winning or losing, } \\
\text { I always do my } \\
\text { best. }\end{array}$ & $\begin{array}{l}\text { Independentemente de ganhar } \\
\text { ou perder, eu sempre faço o } \\
\text { meu melhor. } \\
\begin{array}{l}\text { Obs.: A tradução escolhida } \\
\text { manteve a equivalência } \\
\text { semântica. }\end{array}\end{array}$ \\
\hline 9 & $\begin{array}{l}\text { Even if no one is } \\
\text { watching, I don't } \\
\text { cheat. }\end{array}$ & $\begin{array}{l}\text { Mesmo se ninguém } \\
\text { estiver olhando, eu } \\
\text { não trapaceio. }\end{array}$ & $\begin{array}{lr}\text { Mesmo } & \text { que } \\
\text { ninguém } & \text { esteja } \\
\text { olhando, eu não } \\
\text { trapaceio. }\end{array}$ & $\begin{array}{l}\text { Even though no } \\
\text { one is looking, I } \\
\text { don't cheat. }\end{array}$ & $\begin{array}{l}\text { Even if no one is } \\
\text { looking, I don't } \\
\text { cheat. }\end{array}$ & $\begin{array}{l}\text { Mesmo que ninguém esteja } \\
\text { olhando, eu não trapaceio. } \\
\text { Obs.: A tradução escolhida } \\
\text { manteve a equivalência } \\
\text { semântica. }\end{array}$ \\
\hline 10 & $\begin{array}{l}\text { If I foul someone, I } \\
\text { admit it. }\end{array}$ & $\begin{array}{l}\text { Se eu for desleal } \\
\text { com alguém, eu } \\
\text { assumo. }\end{array}$ & $\begin{array}{l}\text { Se eu cometer uma } \\
\text { falta contra } \\
\text { alguém, eu admito. }\end{array}$ & $\begin{array}{l}\text { If I commit a foul } \\
\text { against someone, I } \\
\text { admit it. }\end{array}$ & $\begin{array}{l}\text { If I foul someone, I } \\
\text { admit it. }\end{array}$ & $\begin{array}{l}\text { Se eu cometer uma falta contra } \\
\text { alguém, eu admito. } \\
\text { Obs.: A tradução manteve } \\
\text { integralmente os componentes } \\
\text { semânticos e literais da versão em } \\
\text { inglês. }\end{array}$ \\
\hline 11 & $\begin{array}{l}\text { In order to win, it } \\
\text { is okay to } \\
\text { purposefully four. }\end{array}$ & $\begin{array}{l}\text { Com a finalidade } \\
\text { de vencer, não faz } \\
\text { mal trapacear de } \\
\text { propósito. }\end{array}$ & $\begin{array}{l}\text { Para vencer, é } \\
\text { aceitável fazer uma } \\
\text { falta proposital. }\end{array}$ & $\begin{array}{l}\text { To win, it is } \\
\text { acceptable to make } \\
\text { an intentional foul. }\end{array}$ & $\begin{array}{l}\text { To win, it is } \\
\text { acceptable to foul } \\
\text { the opponents. }\end{array}$ & $\begin{array}{l}\text { Para vencer, é aceitável fazer } \\
\text { uma falta de propósito. } \\
\text { Obs.: A tradução manteve } \\
\text { integralmente os componentes } \\
\text { semânticos e literais da versão em } \\
\text { inglês. }\end{array}$ \\
\hline 12 & $\begin{array}{l}\text { In order to win, I } \\
\text { could sometimes } \\
\text { be rude and } \\
\text { impolite during the } \\
\text { play. }\end{array}$ & $\begin{array}{l}\text { Com a finalidade } \\
\text { de vencer, algumas } \\
\text { vezes eu poderia } \\
\text { ser mal-educado } \\
\text { durante o jogo. }\end{array}$ & $\begin{array}{l}\text { Para vencer eu } \\
\text { poderia, em alguns } \\
\text { momentos, ser } \\
\text { rude ou mal- } \\
\text { educado durante o } \\
\text { jogo. }\end{array}$ & $\begin{array}{l}\text { To win, I could at } \\
\text { times, be rude } \\
\text { during the game. }\end{array}$ & $\begin{array}{l}\text { To win, I could, at } \\
\text { times, be rude } \\
\text { during the game. }\end{array}$ & $\begin{array}{l}\text { Para vencer, eu poderia, em } \\
\text { alguns momentos, ser rude ou } \\
\text { mal-educado durante o jogo. } \\
\text { Obs.: Optou-se por manter a } \\
\text { palavra rude, com a intenção de } \\
\text { demonstrar o sentimento no } \\
\text { momento da ação de ser mal- } \\
\text { educado. }\end{array}$ \\
\hline 13 & $\begin{array}{l}\text { It is okay to tease } \\
\text { or taunt my } \\
\text { opponent. }\end{array}$ & \begin{tabular}{lr}
\multicolumn{2}{l}{ Não tem problema } \\
provocar \\
insultar & ou \\
adversário. &
\end{tabular} & $\begin{array}{lr}\text { É } & \text { aceitável } \\
\text { provocar } & \text { ou } \\
\text { insultar } & \text { meus } \\
\text { adversários. } & \end{array}$ & $\begin{array}{l}\text { It is acceptable to } \\
\text { provoke or insult } \\
\text { my opponents }\end{array}$ & $\begin{array}{l}\text { It is acceptable to } \\
\text { provoke or insult } \\
\text { my opponents. }\end{array}$ & $\begin{array}{l}\text { É aceitável provocar ou } \\
\text { insultar meus adversários. } \\
\text { Obs.: A tradução escolhida } \\
\text { manteve a a equivalência } \\
\text { semântica. }\end{array}$ \\
\hline 14 & $\begin{array}{l}\text { If I get angry } \\
\text { during } \\
\text { competition, it is } \\
\text { okay to swear at an } \\
\text { opponent. }\end{array}$ & $\begin{array}{lr}\text { Se eu ficar } & \text { com } \\
\text { raiva durante } & \text { uma } \\
\text { competição, } & \text { não } \\
\text { tem } & \text { problema } \\
\text { xingar rrario. } & \text { um } \\
\text { adversário. }\end{array}$ & $\begin{array}{l}\text { Se eu fico com } \\
\text { raiva durante a } \\
\text { competição, é } \\
\text { aceitável xingar } \\
\text { um adversário. }\end{array}$ & $\begin{array}{l}\text { If I get angry } \\
\text { during } \\
\text { competition, it is } \\
\text { okay to swear at an } \\
\text { opponent. }\end{array}$ & $\begin{array}{l}\text { And if I get angry } \\
\text { during a } \\
\text { competition, it is } \\
\text { acceptable to swear } \\
\text { at an opponent. }\end{array}$ & $\begin{array}{l}\text { Se eu ficar com raiva durante } \\
\text { uma competição, é aceitável } \\
\text { xingar um adversário. } \\
\text { Obs.: Optou-se por utilizar o } \\
\text { verbo "ficar" no gerúndio, com o } \\
\text { intuito de mostrar que é uma ação } \\
\text { condicionante para xingar. }\end{array}$ \\
\hline 15 & $\begin{array}{l}\text { It is okay to injure } \\
\text { an opponent in } \\
\text { order to win. }\end{array}$ & $\begin{array}{l}\text { Não tem problema } \\
\text { machucar um } \\
\text { oponente } \\
\text { vencer. }\end{array}$ & $\begin{array}{lr}\text { É } & \text { aceitável } \\
\text { machucar } & \text { um } \\
\text { oponente } & \text { para } \\
\text { vencer. } & \end{array}$ & $\begin{array}{l}\text { It is okay to injure } \\
\text { an opponent in } \\
\text { order to win. }\end{array}$ & $\begin{array}{l}\text { It is acceptable to } \\
\text { hurt an opponent to } \\
\text { win. }\end{array}$ & $\begin{array}{l}\text { É aceitável machucar um } \\
\text { adversário para vencer. } \\
\text { Obs.: Foi escolhida a palavra } \\
\text { "adversários" para substituir a } \\
\text { palavra "oponentes". }\end{array}$ \\
\hline 16 & $\begin{array}{l}\text { I think that if } \\
\text { opponent fall down } \\
\text { during a game, I } \\
\text { should help them } \\
\text { up. }\end{array}$ & $\begin{array}{l}\text { Eu penso que se os } \\
\text { adversários caem } \\
\text { durante um jogo, } \\
\text { eu deveria ajudá- } \\
\text { los a levantar. }\end{array}$ & $\begin{array}{l}\text { Eu acho que se o } \\
\text { adversário cai } \\
\text { durante o jogo, eu } \\
\text { devo ajudá-lo a } \\
\text { levantar. }\end{array}$ & $\begin{array}{l}\text { I think } r \text { if } \\
\text { opponents fall } \\
\text { down during a } \\
\text { game, I should } \\
\text { help them to get } \\
\text { up. }\end{array}$ & $\begin{array}{l}\text { I think if opponent } \\
\text { fall during a game, } \\
\text { I should help them } \\
\text { up. }\end{array}$ & $\begin{array}{l}\text { Eu acho que se adversários } \\
\text { caem durante um jogo, eu devo } \\
\text { ajudá-los a levantar. } \\
\text { Obs.: A utilização da expressão } \\
\text { "eu acho" torna a frase mais } \\
\text { coloquial e de fácil entendimento. }\end{array}$ \\
\hline
\end{tabular}


Adaptação transcultural da Sport Character Scale no Brasil

\begin{tabular}{|c|c|c|c|c|c|c|}
\hline & $\begin{array}{l}\text { Item da versão } \\
\text { original }\end{array}$ & $\begin{array}{l}\text { Versão traduzida } \\
\text { (T1) }\end{array}$ & $\begin{array}{l}\text { Versão traduzida } \\
\text { (T2) }\end{array}$ & $\begin{array}{l}\text { Versão } \\
\text { retrotradução } \\
\text { (RT1) }\end{array}$ & $\begin{array}{l}\text { Versão } \\
\text { retrotradução } \\
\text { (RT2) }\end{array}$ & $\begin{array}{l}\text { Síntese da análise comparativa } \\
\text { da tradução e retrotradução }\end{array}$ \\
\hline 17 & $\begin{array}{l}\text { I feel that } \\
\text { apologizing for a } \\
\text { foul shows respect. }\end{array}$ & $\begin{array}{l}\text { Eu sinto que pedir } \\
\text { desculpas por uma } \\
\text { trapaça demonstra } \\
\text { respeito. }\end{array}$ & $\begin{array}{l}\text { Eu acho que me } \\
\text { desculpar por uma } \\
\text { falta demonstra } \\
\text { respeito. }\end{array}$ & $\begin{array}{l}\text { I feel that } \\
\text { apologizing for a } \\
\text { foul shows respect. }\end{array}$ & $\begin{array}{l}\text { I feel that } \\
\text { apologizing for a } \\
\text { foul shows respect. }\end{array}$ & $\begin{array}{l}\text { Eu sinto que pedir desculpas } \\
\text { por uma falta mostra respeito. } \\
\text { Obs.: A tradução escolhida } \\
\text { manteve a a equivalência } \\
\text { semântica. }\end{array}$ \\
\hline 18 & $\begin{array}{ll}\text { I feel that it } & \text { is } \\
\text { important } & \text { to } \\
\text { encourage } & \\
\text { teammates } & \text { or } \\
\text { opponents } & \text { to } \\
\text { perform well. } & \end{array}$ & $\begin{array}{lr}\text { Eu sinto que é } \\
\text { importante } \\
\text { encorajar colegas } \\
\text { de time } r \text { ou } \\
\text { adversários a se } \\
\text { saírem bem. }\end{array}$ & $\begin{array}{l}\text { Eu sinto que é } \\
\text { importante } \\
\text { encorajar meus } \\
\text { colegas de equipe } \\
\text { ou oponentes a ter } \\
\text { um bom } \\
\text { desempenho. }\end{array}$ & $\begin{array}{l}\text { I feel it is } \\
\text { important to } \\
\text { encourage my team } \\
\text { mates or opponents } \\
\text { to perform well. }\end{array}$ & $\begin{array}{lr}\text { I feel it } & \text { is } \\
\text { important } & \text { to } \\
\text { encourage } & \text { my } \\
\text { teammates } & \text { or } \\
\text { opponents } & \text { to } \\
\text { perform well. } & \end{array}$ & $\begin{array}{l}\text { Eu sinto que é importante } \\
\text { encorajar meus colegas de } \\
\text { equipe ou adversários a ter um } \\
\text { bom desempenho. } \\
\text { Obs.: A tradução manteve } \\
\text { integralmente os componentes } \\
\text { semânticos e literais da versão em } \\
\text { inglês. }\end{array}$ \\
\hline 19 & $\begin{array}{l}\text { I feel bad when an } \\
\text { opponent } \\
\text { injured. }\end{array}$ & $\begin{array}{lr}\text { Eu me sinto mal } \\
\text { quando } & \text { um } \\
\text { adversário é ferido. }\end{array}$ & $\begin{array}{lr}\text { Eu me sinto } & \text { mal } \\
\text { quando } & \text { um } \\
\text { adversário } & \text { se } \\
\text { machuca. } & \end{array}$ & $\begin{array}{l}\text { I feel bad when an } \\
\text { opponent gets hurt. }\end{array}$ & $\begin{array}{l}\text { I feel bad when an } \\
\text { opponent gets hurt }\end{array}$ & $\begin{array}{l}\text { Eu me sinto mal quando um } \\
\text { adversário se machuca. } \\
\text { Obs.: A tradução escolhida } \\
\text { manteve a equivalência } \\
\text { semântica. }\end{array}$ \\
\hline 20 & $\begin{array}{l}\text { I think that it is } \\
\text { important to show } \\
\text { good } \\
\text { manners. }\end{array}$ & $\begin{array}{lr}\text { Eu penso que é } \\
\text { importante } \\
\text { demonstrar boas } \\
\text { maneiras } \\
\text { esporte. }\end{array}$ & $\begin{array}{l}\text { Eu acho que é } \\
\text { importante mostrar } \\
\text { boas maneiras de } \\
\text { jogo. }\end{array}$ & $\begin{array}{l}\text { I think it's } \\
\text { important to } \\
\text { demonstrate "fair } \\
\text { game" practices } \\
\text { and manners. }\end{array}$ & $\begin{array}{l}\text { I think it's } \\
\text { important to show } \\
\text { good } \\
\text { sportsmanship. }\end{array}$ & $\begin{array}{l}\text { Eu acho que é importante } \\
\text { mostrar espírito esportivo. } \\
\text { Obs.: Após a reunião de peritos, a } \\
\text { palavra "boas maneiras" foi } \\
\text { substituída por "espírito } \\
\text { esportivo". }\end{array}$ \\
\hline 21 & $\begin{array}{l}\text { Even if I lose, I } \\
\text { want to be able to } \\
\text { offer my heartfelt } \\
\text { congratulations. }\end{array}$ & $\begin{array}{l}\text { Se eu perder, eu } \\
\text { quero } \quad \text { estar } \\
\text { preparado para } \\
\text { oferecer meus } \\
\text { sinceros parabéns. }\end{array}$ & $\begin{array}{l}\text { Mesmo que eu } \\
\text { perca, eu quero } \\
\text { poder oferecer } \\
\text { sinceros parabéns. }\end{array}$ & $\begin{array}{l}\text { Even if I lose, I } \\
\text { want to be able to } \\
\text { offer my sincere } \\
\text { congratulations. }\end{array}$ & $\begin{array}{l}\text { Even if I lose, I } \\
\text { want to be able to } \\
\text { offer my sincere } \\
\text { congratulations. }\end{array}$ & $\begin{array}{l}\text { Mesmo se eu perder, eu quero } \\
\text { ter condições de oferecer meus } \\
\text { sinceros parabéns. } \\
\text { Obs.: Foi feita uma versão síntese } \\
\text { de } \mathrm{T}_{1} \text { e } \mathrm{T}_{2} \text {, adaptada pela } \mathrm{RT}_{2} \text {, } \\
\text { inserindo a palavra adversário } \\
\text { para melhorar o entendimento da } \\
\text { frase. }\end{array}$ \\
\hline 22 & $\begin{array}{l}\text { After a } \\
\text { competition, } \\
\text { players should } \\
\text { accept the results. }\end{array}$ & $\begin{array}{l}\text { Depois de uma } \\
\text { competição, } \text { os } \\
\text { jogadores } \\
\text { deveriam aceitar os } \\
\text { resultados. }\end{array}$ & $\begin{array}{lr}\text { Depois } & \text { da } \\
\text { competição, } & \text { os } \\
\text { jogadores } & \text { devem } \\
\text { aceitar } & \text { os } \\
\text { resultados. } & \end{array}$ & $\begin{array}{l}\text { Regard less of } \\
\text { game results, } \\
\text { players should be } \\
\text { well mannered. }\end{array}$ & $\begin{array}{l}\text { Regardless of } \\
\text { game results, } \\
\text { players should be } \\
\text { well educated. }\end{array}$ & $\begin{array}{l}\text { Independentemente dos } \\
\text { resultados do jogo, os jogadores } \\
\text { devem ser educados. } \\
\text { Obs.: Optou-se pela retirada da } \\
\text { palavra "bem". }\end{array}$ \\
\hline 23 & $\begin{array}{l}\text { I think that athletes } \\
\text { should always play } \\
\text { fairly. }\end{array}$ & $\begin{array}{lr}\text { Eu penso } & \text { que os } \\
\text { atletas } & \text { deveriam } \\
\text { sempre } & \text { jogar } \\
\text { justamente. } & \end{array}$ & $\begin{array}{l}\text { Eu acho que os } \\
\text { atletas sempre } \\
\text { devem jogar de } \\
\text { forma justa. }\end{array}$ & $\begin{array}{l}\text { I think athletes } \\
\text { should play fairly. }\end{array}$ & $\begin{array}{l}\text { I think athletes } \\
\text { should play fair. }\end{array}$ & $\begin{array}{l}\text { Eu acho que os atletas devem } \\
\text { sempre jogar de forma justa. } \\
\text { Obs.: A palavra sempre foi } \\
\text { adicionada para manter a } \\
\text { equivalência semântica. }\end{array}$ \\
\hline 24 & $\begin{array}{l}\text { I think that players } \\
\text { should follow the } \\
\text { rules even if they } \\
\text { are losing by large } \\
\text { margin. }\end{array}$ & $\begin{array}{l}\text { Eu penso que os } \\
\text { jogadores } \\
\text { deveriam seguir as } \\
\text { regras mesmo que } \\
\text { estejam perdendo } \\
\text { por uma margem } \\
\text { grande. }\end{array}$ & 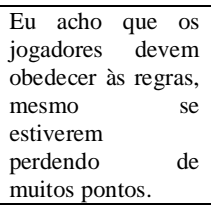 & $\begin{array}{l}\text { I think players } \\
\text { should obey the } \\
\text { rules even if they } \\
\text { are losing by many } \\
\text { points. }\end{array}$ & $\begin{array}{l}\text { I think players } \\
\text { should obey the } \\
\text { rules even if they } \\
\text { are losing a lot of } \\
\text { points. }\end{array}$ & $\begin{array}{l}\text { Eu acho que os jogadores } \\
\text { devem obedecer às regras, } \\
\text { mesmo se estiverem perdendo } \\
\text { de muitos pontos. } \\
\text { Obs.: A utilização da expressão } \\
\text { "eu acho" torna a frase mais } \\
\text { coloquial e de fácil entendimento. }\end{array}$ \\
\hline 25 & $\begin{array}{l}\text { Regardless of the } \\
\text { result of a game, } \\
\text { players should be } \\
\text { courteous. }\end{array}$ & $\begin{array}{l}\text { Independentemente } \\
\text { do resultado do } \\
\text { jogo, os jogadores } \\
\text { deveriam ser } \\
\text { gentis. }\end{array}$ & $\begin{array}{l}\text { Independentemente } \\
\text { dos resultados do } \\
\text { jogo, os jogadores } \\
\text { devem ser bem- } \\
\text { educados. }\end{array}$ & $\begin{array}{l}\text { Regardless of } \\
\text { game results, } \\
\text { players should be } \\
\text { well mannered. }\end{array}$ & $\begin{array}{l}\text { Regard less of } \\
\text { game results, } \\
\text { players should be } \\
\text { well educated. }\end{array}$ & $\begin{array}{l}\text { Independentemente dos } \\
\text { resultados do jogo, os jogadores } \\
\text { devem ser educados. } \\
\text { Obs.: Optou-se pela retirada da } \\
\text { palavra "bem". }\end{array}$ \\
\hline 26 & $\begin{array}{l}\text { Even if I lose, it is } \\
\text { important to accept } \\
\text { the result. }\end{array}$ & $\begin{array}{l}\text { Mesmo se eu } \\
\text { perder, } \\
\text { importante } \\
\text { o resultado }\end{array}$ & $\begin{array}{l}\text { Mesmo que eu } \\
\text { perca, é importante } \\
\text { aceitar o resultado. }\end{array}$ & $\begin{array}{l}\text { Even if I lose, it's } \\
\text { important to accept } \\
\text { the results }\end{array}$ & $\begin{array}{l}\text { Even if I lose, it is } \\
\text { important to accept } \\
\text { the result. }\end{array}$ & $\begin{array}{l}\text { Mesmo se eu perder, é } \\
\text { importante aceitar o resultado. } \\
\text { Obs.: A tradução manteve } \\
\text { integralmente os componentes } \\
\text { semânticos e literais da versão em } \\
\text { inglês. }\end{array}$ \\
\hline 27 & $\begin{array}{l}\text { I always shake } \\
\text { hands with or greet } \\
\text { my opponents even } \\
\text { if I lost. }\end{array}$ & $\begin{array}{l}\text { Eu sempre dou um } \\
\text { aperto de mãos ou } \\
\text { saúdo os meus } \\
\text { adversários, } \\
\text { mesmo se eu } \\
\text { perder. }\end{array}$ & $\begin{array}{l}\text { Eu sempre aperto } \\
\text { as mãos ou } \\
\text { cumprimento meus } \\
\text { adversários quando } \\
\text { eu perco. }\end{array}$ & $\begin{array}{l}\text { Even though I have } \\
\text { lost, I always shake } \\
\text { the hands of my } \\
\text { opponents. }\end{array}$ & $\begin{array}{l}\text { Even though I've } \\
\text { lost, I always shake } \\
\text { hands with my } \\
\text { opponents. }\end{array}$ & $\begin{array}{l}\text { Mesmo que eu tenha perdido, } \\
\text { eu sempre dou um aperto de } \\
\text { mão ou cumprimento os meus } \\
\text { adversários. } \\
\text { Obs.: Foi feita uma inversão na } \\
\text { ordem original durante a RT, para } \\
\text { facilitar o entendimento do item } \\
\text { em questão. }\end{array}$ \\
\hline
\end{tabular}

Fonte: Elaboração própria.

\section{REUNIÃo DE PERITOS}

O quarto passo foi a reunião de peritos, na qual os tradutores e retrotradutores, o juiz de síntese, uma metodologista, um perito em língua e dois atletas analisaram todo material produzido até então $\left(\mathrm{T}_{1}, \mathrm{~T}_{2} \mathrm{~T}_{12} \mathrm{RT}_{1}, \mathrm{RT}_{2}\right)$. Na reunião de peritos foram analisadas todas as versões e materiais produzidos nas fases anteriores, bem como as dúvidas e anotações oriundas destas fases. Os itens foram julgados por cada perito segundo sua equivalência 
semântica, idiomática, cultural e conceitual sendo lhes atribuídos escores -1 (não equivale), 0 (equivale) ou 1 (equivale muito). As notas dos juízes para as equivalências semântica, idiomática, cultural e conceitual podem ser vistas na tabela 1.

Tabela 1: Notas das equivalências semântica, idiomática, cultural e conceitual do Comitê de Peritos.

\begin{tabular}{|c|c|c|c|c|c|c|c|c|}
\hline \multirow[t]{2}{*}{ EQUIVALÊNCIA } & \multicolumn{2}{|c|}{ SEMÂNTICA } & \multicolumn{2}{|c|}{ IDIOMÁTICA } & \multicolumn{2}{|c|}{ CULTURAL } & \multicolumn{2}{|c|}{ CONCEITUAL } \\
\hline & Média & DP & Média & DP & Média & DP & Média & DP \\
\hline SCS1 & 0,75 & 0,50 & 0,5 & 0,58 & 1 & 0 & 1 & 0 \\
\hline $\mathrm{SCS} 2$ & 0,75 & 0,50 & 0,25 & 0,50 & 1 & 0 & 0,75 & 0,50 \\
\hline SCS3 & 0,75 & 0,50 & 0,5 & 0,58 & 1 & 0 & 0,75 & 0,50 \\
\hline SCS4 & 0,5 & 1,00 & 0,5 & 0,58 & 1 & 0 & 1 & 0 \\
\hline SCS5 & 0,75 & 0,50 & 0,5 & 0,58 & 1 & 0 & 1 & 0 \\
\hline SCS6 & 0,75 & 0,50 & 0,75 & 0,50 & 0,75 & 0,50 & 0,75 & 0,50 \\
\hline SCS7 & 0,25 & 0,96 & 0,75 & 0,50 & 0,75 & 0,50 & 0,75 & 0,50 \\
\hline SCS8 & 0,5 & 0,58 & 0,25 & 0,50 & 0,75 & 0,50 & 0,75 & 0,50 \\
\hline SCS9 & 0,75 & 0,50 & 0,75 & 0,50 & 1 & 0 & 1 & 0 \\
\hline SCS10 & 0,75 & 0,50 & 0,75 & 0,50 & 1 & 0 & 1 & 0 \\
\hline SCS11 & 0,75 & 0,50 & 0,75 & 0,50 & 1 & 0 & 1 & 0 \\
\hline SCS12 & 0,25 & 0,96 & 0,25 & 0,96 & 1 & 0 & 1 & 0 \\
\hline SCS13 & 0,25 & 0,96 & 0,75 & 0,50 & 1 & 0 & 1 & 0 \\
\hline SCS14 & 0,5 & 1,00 & 1 & 0 & 1 & 0 & 1 & 0 \\
\hline SCS15 & 0,75 & 0,50 & 0,75 & 0,50 & 1 & 0 & 1 & 0 \\
\hline SCS16 & 1 & 0 & 1 & 0 & 1 & 0 & 1 & 0 \\
\hline SCS17 & 0,75 & 0,50 & 0,75 & 0,50 & 1 & 0 & 0,75 & 0,50 \\
\hline SCS18 & 0,75 & 0,50 & 1 & 0 & 1 & 0 & 1 & 0,00 \\
\hline SCS19 & 0,75 & 0,50 & 0,75 & 0,50 & 1 & 0 & 1 & 0 \\
\hline SCS20 & 0,5 & 0,58 & 0,5 & 0,58 & 0,75 & 0,50 & 0,75 & 0,50 \\
\hline SCS21 & 1 & 0 & 1 & 0 & 1 & 0,00 & 1 & 0 \\
\hline SCS22 & 0 & 1,15 & $-0,5$ & 1,00 & 0 & 1,15 & $-0,5$ & 1,00 \\
\hline SCS23 & $-0,25$ & 0,96 & 0,5 & 1,00 & 0,5 & 0,58 & 0,25 & 0,96 \\
\hline SCS24 & 0,5 & 0,58 & 0,75 & 0,50 & 1 & 0 & 1 & 0 \\
\hline SCS25 & 0 & 1,15 & 0,5 & 0,58 & 1 & 0 & 1 & 0 \\
\hline SCS26 & 1 & 0 & 1 & 0 & 1 & 0 & 1 & 0 \\
\hline SCS27 & 1 & 0 & 1 & 0 & 1 & 0 & 1 & 0 \\
\hline
\end{tabular}

Nota: Média 1 com desvio padrão zero indica avaliação perfeita da respectiva equivalência. Nota cujo desvio padrão leva a média a valores negativos ou médias negativas indica itens que precisam ser revistos.

Fonte: Elaboração própria.

Essa análise descritiva das notas já indicou ao comitê de peritos no início da reunião que os itens 7, 13, 22, 23 e 25 mereciam especial atenção em relação à equivalência semântica; os itens 2,8 e 22 em relação à equivalência idiomática e o item 23 em relação à equivalência conceitual. Culturalmente, todos os itens puderam ser considerados adequados assim como apresentado na $T_{12}$. As discussões começaram por estes itens, e no debate entre os peritos, alcançou-se consenso na manutenção ou modificação dos itens, conforme descrito na sequência.

Os itens $1,3,4,5,6$, e 13 não apresentaram variação significativa entre as traduções, não demonstrando diferenças em equivalência conceitual, cultural, idiomática e semântica, seguindo a intenção da escala original. Nos itens 2 e 20, optou-se pela expressão "espírito esportivo" no lugar de "boas maneiras", com o intuito de manter a equivalência semântica da frase original. 
No item 7 e 21 , por apresentar problemas com relação à equivalência semântica, foi realizada uma versão síntese de $\mathrm{T}_{1} \mathrm{e} \mathrm{T}_{2}$, adaptada pela $\mathrm{RT}_{2}$, e foi inserida a palavra adversário para facilitar o entendimento. Nos itens 8, 9, 10 e 11 as traduções escolhidas mantiveram integralmente os componentes semânticos e literários da versão em inglês. No item 12, optouse por manter a palavra rude, com a intenção de demonstrar o sentimento no momento em que $o$ atleta foi mal-educado, adaptando culturalmente a frase.

No item 14, optou-se por utilizar o verbo "ficar" no gerúndio, com o intuito de demonstrar que é uma ação condicionante para xingar, dirimindo problemas semânticos. No item 15, foi escolhida a palavra "adversários" para substituir a palavra "oponentes". No item 16, a utilização da expressão foi adotada "eu acho", para deixar a frase mais coloquial e de mais fácil compreensão.

No item 17, a tradução escolhida manteve a equivalência semântica. No item 18, a tradução manteve integralmente os componentes semânticos e literários da versão em inglês. No item 19, a escolha foi pela manutenção da equivalência semântica.

No item 22, optou-se pela retirada da palavra "bem". No item 23, a palavra "sempre" foi adicionada para manter a equivalência semântica da frase. No item 24 , a utilização da expressão "eu acho", torna o texto mais coloquial e facilita o entendimento. No item 25 , optou-se pela retirada da palavra "bem". No item 26, a tradução manteve integralmente os componentes literais e semânticos da versão em inglês. No item 27 , foi feita uma inversão na ordem original, conforme sugeridos nas RT, para facilitar o entendimento do item em questão.

\section{PRÉ-TeSTE 1}

O quinto passo foi a realização do pré-teste, em duas etapas. Na primeira se buscou identificar problemas de clareza, entendimento, adequação do layout e consistência das respostas. Foi inicialmente recrutado um grupo de seis atletas, que após ler e assinar o Termo de Consentimento Livre e Esclarecido (TCLE), recebeu a versão da SCS aprovada pelo comitê de peritos. Os participantes responderam a escala, e após a conclusão, foram individualmente entrevistados a respeito da compreensão dos itens, adequação do layout, adequação da resposta assinalada com a reposta desejada.

Foram identificadas dúvidas nos itens $6,7,13,22$ e 26. No item 7, a palavra trash-talk inicialmente havia sido traduzida como "bobagem", o que gerou dúvidas se seriam palavras ofensivas ou não, como palavrões e ofensas mais pesadas. Então, após contato com o autor da escala, a sugestão foi a mudança da palavra "bobagens" por "digo ofensas". No item 13, existiam dois conceitos diferentes, "provocar" e "insultar", que criaram um conflito de entendimento. Então, após análise, a palavra "provocar" foi excluída, permanecendo apenas o sentido mais forte da frase, com a palavra "insultar". No item 10, os participantes apresentaram dúvidas com relação à "falta cometida" ser de caráter normal, usada como recurso de jogo, ou antidesportiva. Após análise, concluiu-se que a falta seria antidesportiva, e o reconhecimento aconteceria após a marcação do juiz, como uma aceitação. Então, adicionou-se "após a marcação do juiz". Os itens 6, 22 e 26 abordavam sobre "os resultados do jogo", na dúvida entre o "resultado" abordar sobre o placar final de jogo ou sobre o desempenho da equipe na partida, independente do resultado final. 
Tabela 2: Avaliação da clareza, pertinência e adequação da resposta na primeira fase do préteste.

\begin{tabular}{ccc|ccc}
\hline $\begin{array}{c}\text { Item } \\
\text { adequado? }\end{array}$ & $\begin{array}{c}\text { Pré-teste 1; } \\
\text { Rodada 1 }\end{array}$ & $\begin{array}{c}\text { Pré-teste; } \\
\text { Rodada 2 }\end{array}$ & $\begin{array}{c}\text { Item } \\
\text { adequado? }\end{array}$ & $\begin{array}{c}\text { Pré-teste 1; } \\
\text { Rodada 1 }\end{array}$ & $\begin{array}{c}\text { Pré-teste; } \\
\text { Rodada 2 }\end{array}$ \\
\hline SCS1 & $100 \%$ & $100 \%$ & SCS15 & $100 \%$ & $100 \%$ \\
SCS2 & $100 \%$ & $100 \%$ & SCS16 & $100 \%$ & $100 \%$ \\
SCS3 & $100 \%$ & $100 \%$ & SCS17 & $94,44 \%$ & $100 \%$ \\
SCS4 & $100 \%$ & $100 \%$ & SCS18 & $100 \%$ & $83,33 \%$ \\
SCS5 & $100 \%$ & $83,33 \%$ & SCS19 & $100 \%$ & $100 \%$ \\
SCS6 & $83,33 \%$ & $100 \%$ & SCS20 & $100 \%$ & $100 \%$ \\
SCS7 & $94,44 \%$ & $100 \%$ & SCS21 & $100 \%$ & $100 \%$ \\
SCS8 & $100 \%$ & $100 \%$ & SCS22 & $83,33 \%$ & $100 \%$ \\
SCS9 & $94,44 \%$ & $100 \%$ & SCS23 & $100 \%$ & $83,33 \%$ \\
SCS10 & $55,55 \%$ & $100 \%$ & SCS24 & $100 \%$ & $100 \%$ \\
SCS11 & $88,88 \%$ & $94,44 \%$ & SCS25 & $94,44 \%$ & $83,33 \%$ \\
SCS12 & $100 \%$ & $83,33 \%$ & SCS26 & $100 \%$ & $100 \%$ \\
SCS13 & $88,88 \%$ & $100 \%$ & SCS27 & $100 \%$ & $100 \%$ \\
SCS14 & $100 \%$ & $100 \%$ & & & \\
\hline
\end{tabular}

Fonte: Elaboração própria.

As dúvidas foram levadas a uma das retrotradutoras, à metodologista e ao autor da escala para serem discutidas, e novamente redigidas. Como forma de dirimir as dúvidas, foram adicionadas instruções mais direcionadas. Após as análises e correções, foi realizada uma segunda rodada da primeira fase do pré-teste, com um novo grupo de participantes, atletas do sexo masculino. Foram adotados os mesmos passos anteriormente descritos. Dessa vez, não houve novas observações relevantes nem dúvidas que ocasionassem mudanças na escala proposta, caracterizando o fim da primeira fase do pré-teste (tabela 2).

\section{PRÉ-TESTE 2}

Na segunda fase do pré-teste, a SCS foi enviada a seis peritos, que fizeram o julgamento da validade de conteúdo. A escala foi enviada por meio eletrônico e o julgamento feito em formulário apropriado. Os resultados indicaram que os itens 16 e 18 poderiam ser considerados para uma reavaliação, tanto por causa de sua clareza quanto pertinência ao constructo avaliado. Todavia, os mesmos foram bem compreendidos pela população alvo e como ainda estão no limite de indicativo (não obrigatoriedade) de revisão, decidimos mantêlos como aprovados (tabela 3). Os itens 17 e 21 foram apontados com potencial problema quanto à sua clareza, mas, mais uma vez verificando os resultados junto à população alvo, não pareceu ser imperativa a mudança. Quanto à pertinência ao constructo avaliado, os itens 1, 4, 8, 9, e 19 foram apontados como potencialmente problemáticos. 
Tabela 3: Validação de Conteúdo da SCS.

\begin{tabular}{ccc|ccc}
\hline Item & $\begin{array}{c}\text { Clareza } \\
\text { I-CVI }\end{array}$ & $\begin{array}{c}\text { Pertinência I- } \\
\text { CVI }\end{array}$ & Item & $\begin{array}{c}\text { Clareza } \\
\text { I-CVI }\end{array}$ & $\begin{array}{c}\text { Pertinência I- } \\
\text { CVI }\end{array}$ \\
\hline SCS1 & 1 & 0,75 & SCS15 & 1 & 1 \\
SCS2 & 1 & 1 & SCS16 & 0,75 & 0,75 \\
SCS3 & 1 & 1 & SCS17 & 0,75 & 1 \\
SCS4 & 1 & 0,75 & SCS18 & 0,75 & 0,75 \\
SCS5 & 1 & 1 & SCS19 & 1 & 0,75 \\
SCS6 & 1 & 1 & SCS20 & 1 & 1 \\
SCS7 & 1 & 1 & SCS21 & 0,75 & 1 \\
SCS8 & 1 & 0,75 & SCS22 & 1 & 1 \\
SCS9 & 1 & 0,75 & SCS23 & 1 & 1 \\
SCS10 & 1 & 1 & SCS24 & 1 & 1 \\
SCS11 & 1 & 1 & SCS25 & 1 & 1 \\
SCS12 & 1 & 1 & SCS26 & 1 & 1 \\
SCS13 & 1 & 1 & SCS27 & 1 & 1 \\
SCS14 & 1 & 1 & &
\end{tabular}

\section{DISCUSSÃo}

O Objetivo desta pesquisa era adaptar culturalmente a Sport Character Scale, que se baseia no modelo de ação moral e propõe o exame das relações entre o caráter no esporte e outras variáveis psicológicas.

Conforme destacaram Martins et al. (2019) e Mouliaá et al. (2020) este processo deve ser minucioso e não pode haver somente a tradução de especialistas, como também a análise das equivalências semânticas, conceituais e realizar a análise de consistência dos itens adaptados comparados aos itens da versão original.

As quatro primeiras etapas - tradução, síntese, retrotradução e reunião do comitê de peritos - ocorreram conforme previsto pelo referencial teórico adotado. Acrescenta-se que os pesquisadores acharam de muita valia a adoção de representantes da população alvo da medida na reunião de peritos, conforme sugerido por Ferreira et al. (2014). A visão "de dentro" desses peritos foi o diferencial na discussão dos itens que foram apontados com problemas de equivalência, em especial a conceitual e idiomática.

Na primeira rodada do pré-teste, foram identificadas dúvidas na rodada inicial nos itens 6, 7, 13, 22 e 26. As dificuldades podem ser resumidas em três pontos: o uso de expressões idiomáticas (trash-talk), o uso de dois verbos distintos com ações distintas na mesma frase (taunt e tease) e o contexto técnico específico do basquete (esporte de alguns participantes do pré-teste) que diferencia falta técnica de falta disciplinar. O primeiro foi tratado na reunião de peritos, mas não se adequando completamente à experiência vivida de nosso contexto de interesse, o esporte. O segundo reflete um problema do instrumento original que já traz essa situação. O terceiro é de uma questão contextual pontual, pois marcadamente os atletas de basquete apresentaram essas dúvidas.

Todas as dúvidas foram tratadas pela metodologista, a retrotradutora e o pesquisador. Todavia, gostaríamos de ressaltar que o autor original do instrumento foi consultado e confirmou todas as readequações sugeridas. Essa consulta ao autor original não aparece no guideline seguido, mas foi essencial para que na segunda rodada do pré-teste houvesse concordância satisfatória em cada um dos aspectos analisados. Assim recomendamos que este recurso seja considerado por outros pesquisadores em seus trabalhos futuros.

Em relação à validade de conteúdo, podemos considerar que, de forma geral, houve uma apreciação dos itens tendendo à adequação. Especialmente para os itens 16, 17, 18 e 21 nos quais foi apontado possível readequação, a análise conjunta com os resultados do préteste 1 minimiza essa necessidade, já que os itens foram considerados claros pelos participantes. Todavia, quando pensamos na pertinência dos itens aos constructos avaliados, 
os itens $1,4,8,9,16,18$, e 19 devem ser checados em um estudo psicométrico futuro, pois é apenas nele que se poderá ratificar esse indicativo de haver algum problema aqui apontado pelos peritos. Esse padrão nos leva a considerar que estudos psicométricos futuros devem considerar a possibilidade de estes itens não pertencerem ao fator teoricamente previsto, apontando para a possibilidade de haver no Brasil, uma estrutura fatorial alternativa. Na verdade, isso é relativamente comum e já foi apontado por outros autores (SWAMI et al., 2011; CAMPANA et al., 2013; ATARI; AFHAMI; SWAMI, 2019).

Findadas estas etapas, consideramos que embora tenham sido necessárias alterações devido às diferenças culturais do país alvo (Brasil) e do país de origem (Estados Unidos), pode-se afirmar que o processo de adaptação cultural da SCS para o contexto brasileiro foi bem-sucedido. Mesmo após alterações, a versão brasileira do questionário demonstrou equivalências conceitual, semântica e idiomática satisfatórias.

O fato de utilizar em nossas amostras somente indivíduos do sexo masculino foi uma das limitações desse trabalho. Como sugestão para trabalhos futuros, partindo agora da escala já adaptada, avaliar e verificar a existência de variações regionais, com relação a diferentes faixas etárias e a adaptação da mesma para o sexo feminino. Desta forma, tais estudos em andamento, possibilitarão o uso de uma escala fidedigna e útil para as medições de variações de caráter no esporte de forma abrangente e satisfatória.

\section{CONCLUSÃo}

O objetivo do presente trabalho foi plenamente alcançado, adaptando culturalmente e verificando a validade de conteúdo da Sport Character Scale (apêndice). O questionário, por sua vez, em suas análises qualitativas e quantitativas, indicou que a versão final aprovada do instrumento é satisfatória e encontra-se pronta para realização do estudo psicométrico. Concluindo este novo processo, ela estará liberada para a aplicação e análise do caráter esportivo dos atletas de modalidades coletivas.

\section{REFERÊNCIAS}

ATARI, M.; AFHAMI, R.; SWAMI, V. Psychometric assessments of Persian translations of three measures of conspiracist beliefs. PloS One, v. 14, n. 4, p. e0215202, 2019.

BEATON, D.; BOMBARDIER, C.; GUILLEMIN, F.; FERRAZ, M. B. Recommendations for the crosscultural adaptation of the DASH \& Quick DASH outcome measures. Chicago: American Academy of Orthopedic Surgeons/Institute for Work \& Health, 2007.

CAMPANA, A. N. N. B.; TAVARES, M. D. C. G. C. F.; SWAMI, V.; DA SILVA, D. An examination of the psychometric properties of Brazilian Portuguese translations of the Drive for Muscularity Scale, the Swansea Muscularity Attitudes Questionnaire, and the Masculine Body Ideal Distress Scale. Psychology of Men \& Masculinity, v. 14, n. 4, p. 376-388, 2013.

FERREIRA, L.; NEVES, A. N.; CAMPANA, M. B.; TAVARES, M. D. C. G. C. F. Guia da AAOS/IWH: sugestões para adaptação transcultural de escalas. Avaliação Psicológica, v. 13, n. 3, p. 457-461, 2014.

JANG, C. Y. Development and validation of the sport character scale. 2013. 177 p. Dissertation (Doctor of Philosophy) - Department of Exercise and Sport Science, University of Utah, Utah, 2013.

KAVUSSANU, M.; BOARDLEY, I. D. The prosocial and antisocial behavior in sport scale. Journal of Sport and Exercise Psychology, v. 31, n. 1, p. 97-117, 2009. 
LEE, M. J.; WHITEHEAD, J.; NTOUMANIS, N. Development of the attitudes to moral decision-making in youth sport questionnaire (AMDYSQ). Psychology of Sport and Exercise, v. 8, n. 3, p. 369-392, 2007.

MARTINS, M. A.; NEVES, A. N.; MOSS, T.; MARTINS, W. H.; PEREIRA, G. V.; PESSÔA, K. V. O.; SILVA, M. H.; ABREU, L. C.. Adaptação cultural em Português Brasileiro da Derriford Appearance Scale-24 (DAS-24) para pessoas vivendo com HIV/AIDS. Journal of Human Growth and Development, v. 29, n. 2, p. 200-215, 2019.

MOUliAÁ, L. R. V.; MURIA, Â. J.; MARTÍNEZ, A. B. L. Multidimensional Attitudes Scale Toward Persons With Disabilities (MAS): tradução e adaptação à língua portuguesa (MAS-PT). MOTRICIDADES: Revista da Sociedade de Pesquisa Qualitativa em Motricidade Humana, v. 4, n. 2, p. 84-99, 2020.

PARK, R. J. Biological thought, athletics and the formation of a 'man of character': 1830-1900. The International Journal of the History of Sport, v. 24, n. 12, p. 1543-1569, 2007.

PLATÃO. A república. São Paulo: Edipro, 2017.

POLLEY, M. The British Olympics: Britain’s Olympic Heritage 1612-2012. London: English Heritage, 2012.

ROUSSEAU, J. J. Emílio ou a educação. São Paulo: Edipro, 2017.

SHIELDS, D. L. L.; BREDEMEIER, B. J. L. Character development and physical activity. Champaign: Human Kinetics Publishers, 1995.

SWAMI, V.; CAMPANA, A. N. N. B.; FERREIRA, L.; BARRETT, S.; HARRIS, A. S.; TAVARES, M. C. G. C. F. The Acceptance of Cosmetic Surgery Scale: initial examination of its factor structure and correlates among Brazilian adults. Body Image, v. 8, n. 2, p. 179-185, 2011.

VALLERAND, R. J.; BRIÈRE, N. M.; BLANCHARD, C.; PROVENCHER, P. Development and validation of the multidimensional sportspersonship orientations scale. Journal of Sport \& Exercise Psychology, v.19, n.2; p. 197-206, 1997.

VANDENBOS, G. R.. Dicionário de psicologia: American Psychological Association APA. Porto Alegre: ArtMed, 2010.

ZAMANZADEH, V.; GHAHRAMANIAN, A.; RASSOULI, M.; ABBASZADEH, A.; ALAVI-MAJD, H.; NIKANFAR, A. R. Design and implementation content validity study: development of an instrument for measuring patient-centered communication. Journal of Caring Sciences, v. 4, n. 2, p. 165-178, 2015.

Recebido em: 19 out. 2020.

Aprovado em: 24 nov. 2020. 


\section{Apêndice:}

\section{Adaptação cultural da Sport Character Scale (Versão aprovada)}

Por favor, leia cada questão. Em seguida, marque um $\mathrm{X}$ ou circule o número que melhor representa a sua resposta para cada item. Seja o mais sincero que puder:

\begin{tabular}{|c|c|c|c|c|c|c|}
\hline & $\begin{array}{c}\text { Discordo } \\
\text { plenamente }\end{array}$ & Discordo & $\begin{array}{c}\text { Discordo um } \\
\text { pouco }\end{array}$ & $\begin{array}{l}\text { Concordo } \\
\text { um pouco }\end{array}$ & Concordo & $\begin{array}{l}\text { Concordo } \\
\text { totalmente }\end{array}$ \\
\hline $\begin{array}{l}\text { 1. Mesmo quando eu estou perdendo por vários } \\
\text { pontos, eu não desisto. }\end{array}$ & 1 & 2 & 3 & 4 & 5 & 6 \\
\hline $\begin{array}{l}\text { 2. Independentemente de ganhar ou perder, eu } \\
\text { demonstro espírito esportivo. }\end{array}$ & 1 & 2 & 3 & 4 & 5 & 6 \\
\hline $\begin{array}{l}\text { 3. Independentemente de ganhar ou perder, eu } \\
\text { sempre sou educado. }\end{array}$ & 1 & 2 & 3 & 4 & 5 & 6 \\
\hline $\begin{array}{l}\text { 4. Mesmo que um adversário trapaceie, eu sempre } \\
\text { mostro espírito esportivo. }\end{array}$ & 1 & 2 & 3 & 4 & 5 & 6 \\
\hline $\begin{array}{l}\text { 5. Independentemente do juiz ou técnico estarem } \\
\text { olhando, eu jogo de forma justa. }\end{array}$ & 1 & 2 & 3 & 4 & 5 & 6 \\
\hline 6. Eu sempre aceito os resultados de um jogo. & 1 & 2 & 3 & 4 & 5 & 6 \\
\hline $\begin{array}{l}\text { 7. Mesmo quando eu fico bravo(a) durante o jogo, eu } \\
\text { não digo ofensas para atrapalhar meu(s) } \\
\text { adversário(s). }\end{array}$ & 1 & 2 & 3 & 4 & 5 & 6 \\
\hline $\begin{array}{l}\text { 8. Independentemente de ganhar ou perder, eu } \\
\text { sempre faço o meu melhor. }\end{array}$ & 1 & 2 & 3 & 4 & 5 & 6 \\
\hline $\begin{array}{l}\text { 9. Mesmo que ninguém esteja olhando, eu não } \\
\text { trapaceio. }\end{array}$ & 1 & 2 & 3 & 4 & 5 & 6 \\
\hline $\begin{array}{l}\text { 10. Se eu cometer uma falta proposital contra } \\
\text { alguém, eu admito após a marcação do juiz. }\end{array}$ & 1 & 2 & 3 & 4 & 5 & 6 \\
\hline $\begin{array}{l}\text { 11. Para vencer, é aceitável fazer uma falta de } \\
\text { propósito. }\end{array}$ & 1 & 2 & 3 & 4 & 5 & 6 \\
\hline $\begin{array}{l}\text { 12. Para vencer, eu poderia, em alguns momentos, } \\
\text { ser rude ou mal-educado durante o jogo. }\end{array}$ & 1 & 2 & 3 & 4 & 5 & 6 \\
\hline 13. É aceitável insultar meus adversários. & 1 & 2 & 3 & 4 & 5 & 6 \\
\hline $\begin{array}{l}\text { 14. Se eu ficar com raiva durante uma competição, é } \\
\text { aceitável xingar um adversário. }\end{array}$ & 1 & 2 & 3 & 4 & 5 & 6 \\
\hline 15. É aceitável machucar um adversário para vencer. & 1 & 2 & 3 & 4 & 5 & 6 \\
\hline $\begin{array}{l}\text { 16. Eu acho que se adversários caem durante o jogo, } \\
\text { eu devo ajuda-los a levantar. }\end{array}$ & 1 & 2 & 3 & 4 & 5 & 6 \\
\hline $\begin{array}{l}\text { 17. Eu sinto que pedir desculpas por uma falta } \\
\text { demonstra respeito. }\end{array}$ & 1 & 2 & 3 & 4 & 5 & 6 \\
\hline $\begin{array}{l}\text { 18. Eu sinto que é importante encorajar meus colegas } \\
\text { de equipe ou adversários a ter um bom desempenho. }\end{array}$ & 1 & 2 & 3 & 4 & 5 & 6 \\
\hline $\begin{array}{l}\text { 19. Eu me sinto mal quando um adversário se } \\
\text { machuca. }\end{array}$ & 1 & 2 & 3 & 4 & 5 & 6 \\
\hline $\begin{array}{l}\text { 20. Eu acho que é importante mostrar espírito } \\
\text { esportivo. }\end{array}$ & 1 & 2 & 3 & 4 & 5 & 6 \\
\hline $\begin{array}{l}\text { 21. Mesmo se eu perder, eu quero ter condições de } \\
\text { oferecer meus sinceros parabéns. }\end{array}$ & 1 & 2 & 3 & 4 & 5 & 6 \\
\hline $\begin{array}{l}\text { 22. Depois da competição, os jogadores devem } \\
\text { aceitar o resultado. }\end{array}$ & 1 & 2 & 3 & 4 & 5 & 6 \\
\hline $\begin{array}{l}\text { 23. Eu acho que os atletas devem sempre jogar de } \\
\text { forma justa. }\end{array}$ & 1 & 2 & 3 & 4 & 5 & 6 \\
\hline $\begin{array}{l}\text { 24. Eu acho que os jogadores devem obedecer às } \\
\text { regras, mesmo se estiverem perdendo de muitos } \\
\text { pontos. }\end{array}$ & 1 & 2 & 3 & 4 & 5 & 6 \\
\hline $\begin{array}{l}\text { 25. Independentemente do resultado do jogo, os } \\
\text { jogadores devem ser educados. }\end{array}$ & 1 & 2 & 3 & 4 & 5 & 6 \\
\hline $\begin{array}{l}\text { 26. Mesmo se eu perder, é importante aceitar o } \\
\text { resultado. }\end{array}$ & 1 & 2 & 3 & 4 & 5 & 6 \\
\hline $\begin{array}{l}\text { 27. Mesmo que eu tenha perdido, eu sempre dou um } \\
\text { aperto de mão ou cumprimento os meus adversários }\end{array}$ & 1 & 2 & 3 & 4 & 5 & 6 \\
\hline
\end{tabular}

